\title{
Supervising Clinical Training
}

Md Gofranul Hoque

The fundamental and primary aim of the medical graduate at their initial period of post graduate training are not fully based on their theoretical knowledge of medical curriculum. The goal of the training should be to produce a doctor who will be fit to handle patient with acute medical problem and have been exposed to a range of medical care giver and developed skill which includes communication, team management and decision making skill with the attitude and ability to work as a member of a team and involved in multi professional practice taking care of the patient as a partner and maintaining high standard of clinical practice to ensure patient safety and care of patient. This goal can only be achieved if the criteria for having quality training is fully working in an institution with the presence of proper supervision and logistics for standard training. In clinical training many individual and agencies play important role either individually or with combined effort and good will help to produce education and training of high standard and internationally accredited.

The quality and standard of training depends on over all structure and organization of health related administrative and educational system. Coordination between the various health care delivery, education and training bodies is mandatory to have a effective training program. The hospital based system of supervision of training should have the opportunity for orientation of trainee about the policies, procedure and structure with the key personal of contact with their roles and responsibility of training and facilities for appraisal, assessment and evaluation of training program. The access to information technology and supports are needed for the supervisor with adequate resources for professional development. The institute should also supports and provide safe physical environment with accommodation and recreational facilities. The program of training should be of appropriate length and duration with the incorporation of element of training and skill which should be learned and practice to apply for the care and well being of the population. The mechanism of supervision of training in the health system setup should have a

1. Principal \& Professor of Medicine Chittagong Medical College, Chittagong system in place to recognize doctors with a level of below standard and to way out for improvement with regular feed back mechanism.

The training program must be prepared in accordance with the basic principle of the curriculum with an aim to develop skilled professional manpower who will provide standard care to the patient, so to materialize this goal their must be defined and specified job description and task of responsibilities both for trainer and trainee. Continuous monitoring and assessment of the supervisor and the trainee doctor will ensure the quality improvement and control of quality and standard of training both to appoint and select the supervisor and preparation of improved version of training program in the future. The standard in the quality of training may not be achieved if the proper accreditation is not conducted by the well organized bodies to the institution where training program is going on. The length of the training, the level of supervision and the provision for feed back and assessment are the few core component of an effective program. The supervisor should supervise the training to the extent of trainees experience and competence. Trainee must provide sufficient information to the supervisor for proper and timely care of the patient. The supervisor must be informed in emergency and before discharge of the patient about the time and day of the admission, the state of the clinical condition of the patient with follow up of improvement and deterioration.

The appointment and selection of supervisor is of paramount importance to over see and execution of clinical training program of the doctor. The primary professional obligation of a doctor is to contribute in the field of education and training of the medical student and health personal. Teaching skill are not inborn attributes of a person. It can learned and nursed. The medical professional who take the responsibilities of the training and teaching should have proper attitude to develop and maintain the skill of teaching and supervision of training in their respective field. He should have the quality to communicate effectively with the patient and relatives and colleagues. He must have the understanding of the basic principle of research and training methodology and have the ability to apprise 
and conduct the assessment and evaluation of the training. The recruitment policies should incorporate those criteria which will ensure the selection of teacher with best ability and aptitude for the profession of teaching and training.

The training bodies i.e. the universities, professional colleges, health authorities must publish criteria with clear cut statement of the training program and recruitment policies for the doctors and supervisors. The goal and objective of the philosophy of training must be understood by both the teacher and trainer within academic institution and health care organization setup. The criteria for selection of clinical educational supervisor should also be drawn up and published, which should have explicit professional and personal attributes and qualities. The appropriate authority should ensure the facilities to provide formal training in teaching skills and in the facilitation of students teaching for all new appointees as teacher. Satisfactory completion of training and evidence of competence should be required before final appointment as teacher.

With the rapid and enormous expansion of the health care education and service facilities in the country a huge number of fresh medical graduates need standard and quality training for pursuing higher education. To over all development of supervision system and recruitment of teacher and trainee a standardization of the training institute should be undertaken without delay. At the present moment we are not in a state of satisfaction to handle the task of training and education of the post graduate doctors of the country. If the complicated landscape of medical education and training is not up graded and restructured as per the perquisite criteria of international standard the medical professional may have to face serious set back for the future development of profession with transfer of technology from the international field of medical science. The authorities of various developed nation has already remodeled and up graded their over all training program with its pragmatic application and regular review. As for example it is worthy to mention that the accreditation council of graduate medical education (ACGME) of USA accredites more than 7000 residency and fellowship program covering 110 specialities. The principal strength of ACGME is the rigorous on site peer based accreditation process for specific program that is required for an employ trainers.
ACGME is governed by the board of director representing stake holders group including trainee. It has the power to withdraw accreditation of all speciality if a single program does not comply with core requirements.

In UK, The Royal Colleges are responsible for setting the standard of training in their respective speciality, while the regional post graduate dean arranges fund for commission and manage post graduate medical training across all specialities and also ensures that the systems and resources are in place to enable the college a standard training. A new statutory body, the post graduate medical education and training board (PMETB) in UK is being established to supervise the training and education sector independent of the government. The mandate of PMETB is to raise standards, to improve supervision of post graduate education and training and to consolidate and strengthen the roles of the colleges and faculties of the university. The governing body of PMETB includes Royal Colleges post graduate deaneries, trainees, clinical teacher, General Medical Council, representative of national health services and patient. Establishment of PMETB clearly signals a sea of change in over sight of post graduate medical education \& training in UK.

To provide quality training and improve the over all standard of medical education of our country the over all system of implementation and supervision of clinical training at various level should be modified and up graded and systematically organized to full fill the requirements of national needs and international standard. Can we do it by adapting with any of the international system or cloning of the improve version of various system of the develop countries to have better trained and qualified doctor for future Bangladesh? 